\title{
Un día en la unidad de hospitalización de psiquiatría
}

\section{A day in the psychiatric inpatient unit}

\section{Um dia na unidade de internação psiquiátrica}

\begin{abstract}
Antonio Rafael Moreno Poyato ${ }^{1}$, María Pilar Montesó Curto², Raquel Suárez Pérez
${ }^{1}$ Escola Superior Infermeria del Mar (ESIM-Adscrita UPF). Parc de Salut Mar de Barcelona

${ }^{2}$ Enfermera. Licenciada en Ciencias Políticas y Sociología. Doctora en Sociología. Profesora Facultad de Enfermería de la Universitat Rovira $i$ Virgili de Tarragona.

${ }^{3}$ Enfermera Especialista en Enfermería de Salud Mental. Máster Universitario en Cuidados de Enfermería: Metodología y Aplicaciones. Enfermera unidad agudos de psiquiatría Hospital del Mar. INAD. Parc de Salut Mar de Barcelona. rc de Salut Mar de Barcelona.

Cómo citar este artículo en edición digital: Moreno Poyato, A.R., Montesó Curto, Ma P. y Suárez Pérez, R. (2015). Un dia en la unidad de hospitalización de psiquiatría. Cultura de los Cuidados (Edición digital) 19, 42. Disponible en: http://dx.doi. org/10.14198/cuid.2015.42.03>

Correspondencia: Escola Superior Infermeria del Mar (ESIM-Adscrita UPF). Parc de Salut Mar de Barcelona. C/ Dr. Aiguader, 80 Despatx 61.317 08003-Barcelona.

Correo electronico: armorenop@parcdesalutmar

Recibido: 10/01//2015; Aceptado: 10/06/2015
\end{abstract}

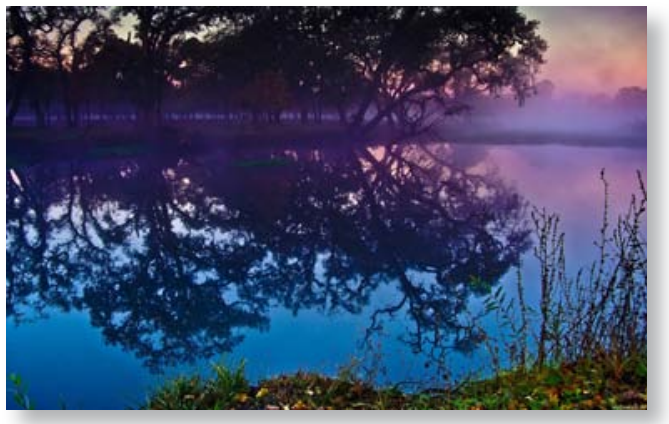

\section{ABSTRACT}

We present the story of what could be the experience of a hospitalized person in whatever psychiatric unit. The data are generated by non-participant observation and care experience of the authors. The protagonist person is involuntarily admitted in a psychiatric acute unit; he has received the diagnostic label of psychosis by the "system". Through his eyes, the authors reflect about perceptions and experiences that happen him in relation to the daily workings of the hospital, and of course with the care received by nurses in the unit.

Keywords: mental health nursing, therapeutic relationship, quality of care, involuntary admission.

\section{RESUMO}

Nós apresentamos a história do que poderia ser a experiência de uma pessoa internada em qualquer unidade psiquiátrica. Os dados são gerados pela observação não participante e experiência de cuidado dos autores. A pessoa protagonista é involuntariamente internado em uma unidade psiquiátrica aguda; ele recebeu o rótulo diagnóstico de psicose pelo "sistema”. Através de seus olhos, os autores refletem sobre as percepções e experiências que lhe suceder em relação aos trabalhos diários do hospital, e, claro, com o cuidado recebido por enfermeiras da unidade.

Palavras-Chave: enfermagem de saúde mental, relação terapêutica, qualidade dos cuidados admissão involuntária.

\section{RESUMEN}

Se presenta el relato de la que podría ser la experiencia vivida por una persona hospitalizada en una unidad de psiquiatría cualquiera. Los datos se generan mediante la observación no participante, entrevistas informales y la propia experiencia asistencial de los autores. 
La persona protagonista está hospitalizada de forma involuntaria en una unidad de agudos de psiquiatría, ha recibido del "sistema" la etiqueta diagnóstica de psicosis. A través de su mirada, los autores reflexionan en torno a las percepciones y vivencias que le acontecen en relación con el devenir cotidiano del hospital, y por supuesto con el cuidado recibido por las enfermeras de la unidad.

Palabras clave: enfermería de salud mental; relación terapéutica; calidad de cuidados; hospitalización involuntaria

\section{El despertar}

Abro los ojos y miro a mi alrededor.....son las siete y cuarto de la mañana y estoy en la misma habitación que ayer. Se trata de una habitación de unos quince metros cuadrados con dos camas, dos mesitas de noche y dos armarios cerrados con llave, además hay un baño con ducha. Posee un amplio ventanal con vistas excelentes, pero lo cambiaría todo por no estar aquí. Efectivamente, sigo encerrado en la sala de psiquiatría, y ya van dos días.

Apenas a cincuenta centímetros de mi cama duerme otra persona que hasta hace escasas doce horas era totalmente desconocida para mí. Aún no me atrevo a decirle nada, me da miedo, respeto. Ayer gritó a las enfermeras de la tarde, por la noche empujó a una señora y lo tuvieron que atar. Sin hacer mucho ruido me acerco al baño e intento dirigirme hacia el pasillo de la unidad. Mi habitación es la primera de las doce habitaciones dobles a derecha y cinco más a izquierda que cuento. Justo detrás tengo la puerta de salida al vestíbulo de los ascensores, esa puerta está cerrada (como todas aquí), y para mí es la puerta de la libertad. Por allí entran y salen las enfermeras, los médicos, las familias que acuden de visita en la tarde; pero sobre todo, por allí salen quienes recuperan su libertad, por allí es por donde quiero salir lo antes posible....Al final del pasillo intuyo la presencia de dos internos que ya están despiertos, se dirigen a una sala común donde hay mesas, una televisión y sillones. Es la única sala de estar de la unidad, donde paso casi todo el día, a excepción de los breves espacios en que me permiten estar en la habitación. Avanzo por el pasillo y en la mitad del mismo encuentro la enfermería; como ya son las siete y media, están reunidos el turno de la mañana y de la noche; cuento casi diez personas dentro del control. Las enfermeras de la mañana están muy atentas a lo que explica la enfermera de la noche, que parece que tiene bastantes ganas de irse (yo también). Si me acerco un poco a la cristalera que impide el paso al interior de la enfermería, podría escuchar lo que están diciendo, pero la verdad es que no me apetece. Además, de frente vienen los otros dos pacientes que estaban despiertos, se dirigen hacia el control y en apenas un segundo ya están picando en la puerta de la cristalera. Una enfermera de la noche les dice que se esperen, pero ellos siguen picando. La verdad es que prefiero seguir hasta el comedor y sentarme en un sillón a ver como amanece sobre el mar. Las vistas desde el comedor, en la octava planta del edificio, son espectaculares, y a esta hora de la mañana la mayoría de enfermos todavía duermen, y la sala respira cierta tranquilidad.

Quince minutos después, se oye salir al equipo de la noche por la "puerta de la libertad". Ahora, el volumen de voz en la enfermería es más elevado, el turno de la mañana sigue reunido y supongo que están planificando la jornada. Después, preguntaré a las enfermeras si saben si hoy me visitará el médico, quiero preguntarle si hoy me voy de alta, no entiendo por qué todavía estoy aquí. 


\section{Los otros}

Poco a poco, el comedor se va llenando de pacientes, a mi eso me incomoda, me siento observado, a veces tengo miedo. Sinceramente no sé por qué deben estar aquí, pero su aspecto me hace pensar que muchos de ellos sí que están locos; parecen descuidados, algo sucios, su mirada está perdida, da la sensación que estén en otro mundo. En ocasiones, hacen gestos y gritan sin que les haya pasado nada. Sin embargo, otras veces les veo hablar con toda normalidad. No entiendo nada, pero siento miedo. En cambio, hay otro tipo de personas que parecen completamente normales. Hay una chica, muy joven, que es muy cariñosa. Alguna vez se ha sentado a mi lado y me toca y me acaricia. Por un lado, me acompaña y me hace sentir bien, pero por otro me incomoda y tengo la sensación de que quiera algo de mí. No sé, no me atrevo a decirle nada, tiene mucho genio. Ella siempre está hablando con todos y parece que quiera ayudar. Sorprendentemente, con la mayoría de enfermeras no se lleva bien, la he visto enfrentarse más de una vez, incluso creo que un día terminó atada en la cama. También debo decir, que existe otro grupo de personas que se encuentran francamente tristes, realmente están muy deprimidos. Están siempre sentados en el mismo lugar, no se mueven en todo el día si las enfermeras o la familia no les estimulan de alguna manera. Su cara no refleja ninguna expresión, hacen todo muy lentamente, apenas comen. Aún así, percibo gran sufrimiento y angustia en ellos.

\section{Las enfermeras}

Por fin salen algunas enfermeras del control, acuden al comedor y con una voz dulce y agradable nos dan los buenos días (cómo se agradece la amabilidad en un lugar como éste). Muchos de los enfermos las siguen has- ta una habitación donde guardan la lencería y otros objetos de aseo, para pedirles toallas para ducharse, cuchillas para afeitarse o colonia. Mientras tanto, otras enfermeras están dentro del control preparando medicación, éstas parecen tener un rango mayor, cuando hablan a las otras intuyo cierta jerarquía. Como supongo que mi compañero de habitación debe estar todavía durmiendo, creo que aprovecharé para pedir toallas y ducharme. En la cola del ropero somos más de seis personas, varios piden cosas a la vez y de forma exigente, la enfermera pacientemente responde a unos y a otros. Ya me toca a mí; le pido las toallas y le pregunto por el médico. Su respuesta ya no me parece tan cordial y paciente como a los anteriores, me dice que le pregunte a mi enfermera de referencia que está en el control. Como parece que no sabe o no quiere decirme nada, prefiero ir a la enfermería. La verdad es que no sé realmente quién es mi enfermera de referencia, me dirigiré a cualquiera de las que hay. Llamo a la puerta del control y sale una de las enfermeras, le explico que quiero saber si hoy me iré de alta. Ella llama a otra enfermera que hay en el otro lado de la enfermería, le pregunta si ella me lleva a mí, y esta asiente con la cabeza $\mathrm{y}$ dice que ya viene. Cuando llega me pregunta que qué quiero, le explico que quiero saber si hoy me voy de alta. Me dice que luego posiblemente suba el médico, y que él ya me dirá, pero yo me quedo con la sensación de que me oculta algo, ella seguramente sabe más de lo que ha dicho. Mejor voy a ducharme...

\section{El desayuno}

Hacia las ocho y media llega el carro con los desayunos, las enfermeras avisan a todos los pacientes para que vayan y se sienten en las mesas de la sala común. En apenas cinco minutos, estamos treinta pacientes sentados 
esperando a que las enfermeras nos traigan las bandejas con el desayuno. El sol ya está más alto e incide por los ventanales de forma directa e incluso molesta, una señora grita enfadada que ella es el sol, el puto sol. Mientras tanto, unos hablan con otros sin hacerle caso y con mayor entusiasmo que en la cena de anoche, supongo que como todavía no han tomado medicación hoy...Cuando han servido los desayunos el silencio se apodera de la sala, todo el mundo se concentra en la comida, unos para devorarla y otros parece que no la quieran ni probar. De repente, la señora que gritaba antes discute con su compañero respecto al pan, se enfada mucho, le grita y se levanta con la intención de irse. Rápidamente las enfermeras acuden y la llaman al orden con respeto, ella obedece. Seguidamente, llegan las otras enfermeras, cada una lleva una bandeja con vasitos con el nombre de cada uno de los pacientes, en ellos va la medicación. Las enfermeras se van desplazando entre las mesas y van buscando a sus pacientes. Una vez están a su lado, sin apenas preguntar (supongo que los conocen), se acercan y vuelcan el vaso dejando caer las pastillas sobre la mano del enfermo. Justo en este momento, se me aproxima la enfermera con la que hablé antes y me pide que ponga la mano para volcar el contenido del vaso, observo que hay una pastilla amarilla y otra blanca, la amarilla es como la que tomé anoche pero la blanca es nueva. Le pregunto que si esa pastilla es para mí, qué es y para qué sirve. Ella me contesta que es para tranquilizarme, que me la tengo que tomar y que luego le pregunte al médico. Vuelvo a tener la sensación de que me oculta información. Mientras tanto, a mi lado una señora mayor le dice a su enfermera que ayer tuvo diarreas y que prefiere no tomar el laxante, la enfermera no se lo da. Al otro lado de la mesa, la señora que estaba enfadada afir- ma irónicamente: ¡aquí no somos dueños de nuestras vidas....!

\section{El devenir de la mañana}

Han terminado los desayunos, espero que suba pronto el médico. Encuentro abierta la puerta de mi habitación; Allí están dos enfermeras hablando con mi compañero de habitación, que todavía está atado. Una le dice que qué necesidad tiene de estar así, que no empuje a nadie. Él le contesta enfadado que la culpa fue de la gitana. Una enfermera parece que manda más que lo otra; ésa que manda más, le explica a mi compañero cómo van a ir las cosas; le pregunta si quiere volver a casa pronto, que si eso es así que debe tomar la medicación, le da las pastillas y después se va, la otra se queda en la habitación y le pregunta si prefiere que le desate una mano para desayunar solo. Mi compañero parece algo más relajado...pero prefiero no entrar en este momento a la habitación y me voy.

Las horas en la unidad pasan lentas, sentado en la sala común tengo un ojo puesto en la playa y otro en la puerta de la sala, confío en que venga pronto el médico. De pronto veo que mi compañero está suelto, parece tranquilo y viene hacia la sala. Quizás es un buen momento para ir a la habitación. Allí me encuentro a las enfermeras haciendo las camas, me saludan cordialmente, parecen otras distintas a las que estaban dando la medicación y el desayuno antes. Verlas así me hace sentir bien. Aprovecho para preguntarles por el médico, me dicen que pregunte a mi enfermera, pero dicen que hoy no creen que venga ya que hay una jornada importante en el hospital. De todas formas, me preguntan que qué necesito, yo les explico que no entiendo por qué estoy aquí y que quiero irme de alta. Ante esto me dicen que ellas se lo dirán a mi enfermera. Más tarde 
me busca la enfermera, se sienta a mi lado en la cama y me pregunta cómo estoy. Le explico lo que quiero y cómo me siento. Ella me dice que el médico no vendrá hoy, pero que aunque viniera seguramente no me daría el alta, ella cree que llevo poco tiempo y que todavía no estoy bien, no estoy en condiciones para poder irme. La verdad es que no entiendo el motivo, pero no tengo más remedio que aceptarlo.

En la sala común está la señora que antes estaba enfadada dibujando y pintando. La veo relajada y concentrada, lo hace muy bien, hace unos dibujos formidables. En un lado del comedor hay una estantería donde se guarda material de papelería y juegos, supongo que se puede coger y usar libremente. La chica joven me dijo que hace tiempo había una persona del equipo que se encargaba de hacer actividades con los pacientes, dice que era muy entretenido y que era un espacio de trabajo conjunto entre pacientes y enfermeras. Otros pacientes están viendo la tele, parece que la miran pero no estoy seguro de que entiendan lo que están viendo. De vez en cuando pasa por allí alguna enfermera o auxiliar y nos pregunta que cómo estamos y le dan agua a las personas mayores. Me han dicho que las enfermeras están divididas en dos niveles; las que dan la medicación y mandan más son las enfermeras y las que nos dan las toallas y hacen las camas son las auxiliares. La verdad es que para mi todas son iguales, unas más simpáticas y atentas y otras menos.

Una enfermera va gritando por el pasillo que es la hora de comer, parece que ya ha llegado el carro de las comidas. Ahora se repite el procedimiento del desayuno, todos nos sentamos en las mesas y ellas nos traen las bandejas, pregonando previamente nuestro nombre. Esta vez, está también mi compañero de habitación. Es curioso, pero a pesar de que co- memos mucha gente junta, apenas hay diálogo ni conversación, salvo el de las enfermeras haciendo alguna indicación a algún paciente, la verdad es que a mí no me apetece nada hablar con nadie. A medida que vamos terminando, llevamos la bandeja al carro y nos dirigimos a nuestra habitación, es el momento de la siesta.

\section{Esperando la familia se apaga la tarde}

Abro los ojos y miro a mi alrededor, son las dos y media de la tarde, estoy en la misma habitación que esta mañana. Está claro que hoy tampoco poco podré irme. Observo que mi compañero no está en la habitación. Apenas he dormido una hora, pero me siento con más energía, la medicación no me tiene tan atontado. Salgo de la habitación y me asomo al pasillo, el resto de enfermos van arriba y abajo, parecen leones enjaulados. Mientras tanto, en el control de enfermería están reunidos los turnos de mañana y de tarde, son cerca de diez personas, se oye mucho jaleo, varias enfermeras hablan a la vez, discuten, creo que hablan de mi compañero de habitación.

A las cuatro de la tarde empiezan las visitas familiares, por supuesto, la tarde se hace más amena si recibes visita de la familia, si no se puede hacer eterna, no hay nada que hacer. En cualquier caso, hasta las cuatro intento ver un rato la televisión en la sala común, pero a veces me cuesta concentrarme por lo que prefiero pasear por el pasillo. Las auxiliares de la tarde salen a saludarnos, son jóvenes $y$ parecen más cercanas en el trato. Las enfermeras, mientras tanto supongo que preparan la medicación de la tarde, porque al rato salen con las mismas bandejas del desayuno, y creo que con los mismos vasitos con nuestros nombres. Van buscando a los pacientes, y allí donde estén les dan las pastillas. Mi enfermera se ha cruzado conmigo en el pasillo, me ha 
saludado, me ha preguntado cómo estaba y me ha puesto la pastilla en la mano, es la amarilla de siempre, ¿cuál sería la blanca de esta mañana?... mientras pienso en eso, la enfermera me anima a que tome la medicación. Noto cierta prisa en terminar, pero me lo dice con un tono de humor que hace que no me lo tome a mal. Casi no he tragado la pastilla que veo que ya le está dando la medicación a otro paciente que va por el pasillo...

De repente, todas las enfermeras empiezan a correr por la unidad. Según puedo escuchar hay un ingreso. Parece que no han avisado desde urgencias. Las caras de las enfermeras han cambiado, ya no están tan relajadas y sonrientes como antes. Denotan cierta inquietud y tensión. Yo siento temor. Una paciente empieza a gritar en el pasillo, dice que necesita un cigarrillo, parece estar muy desesperada. Una enfermera va junto a ella y trata de explicarle que no se puede fumar, que se le puede dar algo de medicación para que se relaje, en principio la mujer dice que lo intentará pero su cara refleja estar mal. En ese momento, aparece el celador con una camilla, y en ella una persona tapada hasta arriba. Rápidamente las auxiliares corren por el pasillo y acompañan al celador a la habitación donde alojarán a la persona que ingresa. Una de las enfermeras también se dirige a la habitación con atadores en las manos. La paciente que quería fumar sigue muy nerviosa y se dirige hacia la puerta de entrada y salida, una de las enfermeras se va hacia ella para intervenir, pero parece que está con un ojo en ella y el otro en la habitación del ingreso, de hecho está la puerta de la habitación abierta, y mientras ve a sus compañeras interviene con esta paciente. Le indica que no pase en dirección hacia la puerta de salida. Le dice que ya se escapó el otro día. La mujer no parece entenderlo y se pone cada vez más nerviosa. Los demás vemos la escena desde la distancia, la verdad es que no sabemos cómo va a terminar, yo estoy algo asustado. Finalmente, la enfermera decide darle medicación a esta paciente y se la lleva del lugar del ingreso. La acompaña y parece que progresivamente se va tranquilizando. Al rato salen el resto de personas del equipo de la habitación y se van a la enfermería, vuelven a estar más relajadas. La calma vuelve paulatinamente a la sala.

Menos mal que ha venido mi madre a verme, le pido que me saque de aquí. Le insisto que a mí no me pasa nada y que ella puede pedir el alta por mí. Le explico que las pastillas me están atontando, que no soy el mismo. Ella me dice que no puede hacer nada, que debe ser el médico, pero creo que no me entiende y que no hace lo suficiente por ayudarme. Ha llegado la hora de marcharse, la acompaño. Al pasar a la altura de la enfermería, aprovecha que ésta está abierta para preguntarle a la enfermera si mañana podrá hablar con el médico. La enfermera, desde unos tres metros de distancia y sin levantarse de la silla, le responde que no lo sabe, que llame por teléfono por la mañana.

Es la hora de cenar y ya estamos todos otra vez sentados en las mesas del comedor, pero a pesar del número de personas que estamos allí, el sentimiento de soledad vuelve a apoderarse de mí. Me siento extraño y obligado a estar en un lugar insólito. Apenas ceno. El sueño me invade y creo que es mejor ir a la cama.

\section{La noche}

Apenas tengo la sensación de haber caído dormido, que acude una enfermera a mi habitación vociferando que hay que ir a tomar la medicación. Miro el reloj, son las diez y media de la noche, mi sensación de rareza ahora es aún mayor. Me noto tenso, me cuesta pensar. La enfermera me vuelve a recordar que debo ir 
al comedor a tomar la medicación. Por el pasillo todos nos dirigimos hacia el fondo, donde se forma una cola y nos ofrecen comida, bebida, y cómo no también otra vez la dichosa medicación. Cuando llega mi turno veo que vuelve a estar la pastilla blanca. Esta vez me niego a tomarla y le digo a la enfermera que me explique qué es. Ella me dice que después lo hablamos, que termina con el resto de pacientes y me atiende. Una vez ha terminado de dar la medicación a toda la cola, me llama por mi nombre y se sienta a mi lado. Me pregunta si no la había tomado ya antes y al responderle que no, me dice que va a mirar mi historia clínica y que luego viene y me dice. Al rato acude y me informa que la he empezado a tomar esta mañana, que se trata de una medicación que pautó el médico en el día de ayer tras la visita, y que sirve para estabilizar el ánimo. Al menos ya sé para qué sirve. Espero poder conciliar de nuevo el sueño....

Alguien susurra a mi lado, es la enfermera de anoche. Me da los buenos días y me explica que debe hacer una extracción de sangre para una analítica, no me gustan las agujas pero confío en ella.

De nuevo abro los ojos y miro a mi alrededor. Ya no puedo conciliar el sueño, son las siete de la mañana de mi tercer día en la unidad de psiquiatría. Hoy espero saber algo más sobre lo que me está pasando...

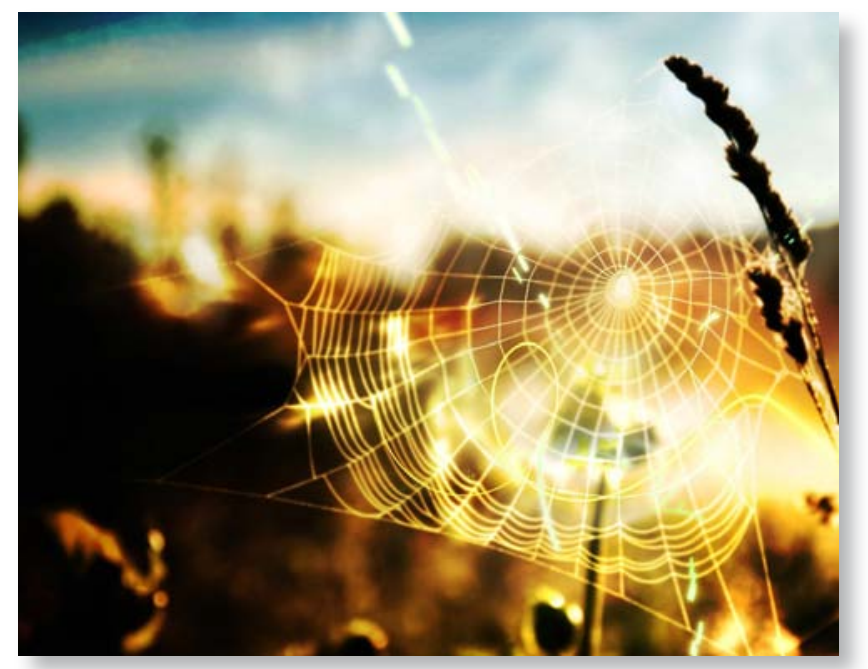

